\title{
TRAJETÓRIAS DE ACUMULAÇÃO DE CAPACIDADES TECNOLÓGICAS: O CASO DA INDÚSTRIA LEITEIRA DO SUDOESTE DO PARANÁ
}

\section{Trajectories of technological capabilities accumulation: The Case of Dairy Industry in the Southwest of Paraná State}

Janaina Piana

E-mail: janainapiana@utfpr.edu.br

Doutora em Administração pela Fundação Getulio Vargas; Mestra em Administração pela Universidade Federal de Santa Catarina; Professora Adjunta na Universidade Tecnológica Federal do Paraná.

Endereço para contato: Rua Marcílio Dias, 635, Campus Apucarana, 86812-460, Apucarana, Paraná,

Elizângela Mara Carvalheiro

E-mail: elizangelam@utfpr.edu.br

Doutora em Desenvolvimento Rural pela Universidade Federal do Rio Grande do Sul; Mestra em Desenvolvimento Regional e Agronegócio pela Universidade Estadual do Oeste do Paraná; Professora Adjunta na Universidade Tecnológica Federal do Paraná. https://orcid.org/0000-0003-0596-3714 


\section{Resumo}

O estudo analisa as trajetórias de acumulação de capacidades tecnológicas e processos de aprendizagem da indústria leiteira da região Sudoeste do Estado do Paraná. Considerando a importância que essa atividade tem na economia paranaense-o Estado representa $12,9 \%$ da produção nacional-tem havido um crescente interesse no entendimento do potencial inovador e tecnológico dessa indústria, porém muito pouco tem sido investigado, especialmente no contexto da região Sudoeste do Paraná. Por meio de um desenho de pesquisa qualitativo baseado em evidências primárias coletadas principalmente por meio de entrevistas em quatro empresas, observou-se que em um laticínio se desenvolveu uma trajetória de acumulação de capacidades tecnológicas que resultou em capacidade de inovação intermediária; e, em três laticínios, desenvolveu-se uma trajetória de estagnação em capacidades tecnológicas de produção básica, em dois deles há mais de 30 anos. Nesses, os processos de aprendizagem se balizaram principalmente em treinamentos e assistência técnica. Também, considera-se que os laticínios, independente da trajetória, possuem foco na produção do queijo Mussarela, observando-se poucos movimentos de diversificação de produto. Sugere-se premência no apoio de políticas públicas locais de inovação que possam estimular o processo inovativo, especialmente em produto.

Palavras-chave: Capacidades tecnológicas. Processos de aprendizagem. Indústria leiteira.

\section{Abstract}

The study analyzes as trajectories of technology accumulation and learning processes of the dairy industry of the Southwest region of Paraná State. Considering the importance that this activity has for the economy of Paraná-the Paraná represents $12.9 \%$ of national productionthere has been a growing interest in understanding the innovative and technological potential of this industry, however very little has been investigated, especially in the southwest of Paraná state. This research used a qualitative approach and a design based on primary evidence collected mainly through interviews in four companies. The study find that one dairy firm developed a trajectory of accumulation of technological capabilities that resulted in intermediate technological capability of innovation; and, three dairies firms remained stagnated in basic production technological capabilities, two of them for more than 30 years. In these three cases the learning mechanisms were based only in training and technical assistance. In addition, it is considered that dairy products, regardless of the trajectory of the firms, are focused on the production of Mozzarella cheese with scarce of product diversification. It is suggested urgency in support in local innovation policies be encouraged to stimulate the innovation process, especially in products.

Keywords: Technological capabilities. Learning processes. Dairy industry.

\section{INTRODUÇÃO}

A presente pesquisa insere-se no tema de gestão da inovação, especificamente no que se refere ao processo de acumulação de capacidades tecnológicas em nível de empresa no contexto de indústrias relacionadas a recursos naturais em economias emergentes. $A$ capacidade tecnológica refere-se ao estoque de recursos necessários para realizar atividades de produção e inovação, como habilidades, conhecimentos e experiências que podem estar alocados dentro da empresa ou distribuídos entre outras organizações vinculadas à empresa 
(Bell \& Pavitt, 1993, 1995). O acúmulo de capacidades tecnológicas de maneira equivalente aos líderes globais de inovação da mesma indústria permite às empresas de economias emergentes alcançar posição de liderança mundial em inovação. Para que empresas de economias emergentes acumulem capacidades tecnológicas, elas precisam se engajar em esforços de aprendizagem tecnológica. A aprendizagem tecnológica trata-se do esforço deliberado das empresas ou indústrias para criar bases de conhecimento para a construção de capacidades tecnológicas que permitam à empresa realizar atividades de produção e inovação (Bell \& Figueiredo, 2012). A acumulação de capacidades tecnológicas e os esforços de aprendizagem ajudam a explicar o comportamento de trajetórias ou percursos de acumulação de capacidades tecnológicas em empresas e indústrias.

Durante os últimos 40 anos muito se avançou no campo da pesquisa sobre acumulação de capacidades tecnológicas, em nível de empresas em economias emergentes. Os estudos forneceram análises sobre fontes (Dantas \& Bell, 2011; Figueiredo \& Piana, 2016), velocidades (Ariffin, 2010), trajetórias (Lee \& Lim, 2001) e implicações da acumulação de capacidades tecnológicas (Shan \& Jolly, 2012) em diferentes empresas e setores de economias emergentes. Porém, essas pesquisas não têm gerado respostas ainda suficientes para a compreensão da natureza e dinâmica de trajetórias de acumulação de capacidades tecnológicas e suas fontes (processos de aprendizagem). Essa falta de compreensão é ainda mais acentuada em indústrias relacionadas a recursos naturais (Figueiredo \& Piana, 2018; Katz \& Pietrobelli, 2018), como a indústria leiteira.

A indústria leiteira brasileira, em 2014, alcançou a quarta posição no ranking mundial de países com a maior produção de leite, com 32,5 bilhões de litros de leite (Secretaria de Estado da Agricultura e do Abastecimento-Departamento de Economia Rural [SeabDeral], 2016). A Região Sul está na primeira posição no ranking das grandes regiões, com $34,7 \%$ da produção nacional. O Estado do Paraná é o terceiro maior produtor do Brasil, com 12,9\% do total nacional (Secretaria da Comunicação Social [SCS], 2015).

O Paraná concentra três principais bacias de produção de leite: Centro-Oriental, Oeste e Sudoeste. Essas três bacias envolvem 95 municípios e são responsáveis por $53 \%$ da produção estadual de leite (Instituto Paranaense de Assistência Técnica e Extensão Rural [EMATER], 2010). Entre as bacias leiteiras de maior destaque do Paraná está a região Sudoeste (foco deste estudo), que, segundo dados do Seab-Deral (2016), produziu 1.095.843 milhões de litros, representando $3 \%$ da produção brasileira e $25,2 \%$ da produção paranaense no ano de 2013.

Apesar da relevância que a indústria leiteira tem para o Brasil e o Paraná, ainda pouco se sabe sobre o potencial inovador e tecnológico dessa indústria. Dessa forma, este artigo objetiva analisar a trajetória de acumulação de capacidades tecnológicas, bem como o seu relacionamento com os processos de aprendizagem em empresas da indústria leiteira do Sudoeste do Paraná. Para atender ao objetivo proposto, foi utilizada uma 
abordagem metodológica qualitativa e longitudinal. Tal abordagem foi operacionalizada por estudos de caso com base em evidências empíricas de primeira mão coletadas por meio de trabalho de campo.

Em termos de trajetórias, a pesquisa demonstrou que em um laticínio se desenvolveu uma trajetória de acumulação de capacidades tecnológicas que resultou em capacidade de inovação intermediária; e, em três laticínios, desenvolveu-se uma trajetória de estagnação em capacidades tecnológicas de produção básica, em dois deles há mais de 30 anos. Nesses, os processos de aprendizagem se balizaram principalmente em treinamentos $e$ assistência técnica. Também, considera-se que os laticínios, independente da trajetória, possuem foco na produção do queijo Mussarela, observando-se poucos movimentos de diversificação de produto.

Diante disso, sugere-se premência no apoio de políticas públicas locais de inovação que possam estimular o processo inovativo, especialmente em produto. $E$, em termos de ações empresariais, recomenda-se maior sensibilização das empresas para o desenvolvimento de esforços voltados a diferentes mecanismos de aprendizagem que permitam o aprofundamento de capacidades tecnológicas.

\section{TRAJETÓRIA DE ACUMULAÇÃO DE CAPACIDADES TECNOLÓGICAS E PROCESSOS DE APRENDIZAGEM}

O desenvolvimento econômico está usualmente associado ao desempenho inovador e tecnológico em nível de organizações. Esse desempenho, por sua vez, depende da maneira como as empresas acumulam suas capacidades tecnológicas e alcançam o catch-up tecnológico (Lacasa \& Günther, 2019; Lacasa, Jindra, \& Radosevic, 2018; Lee \& Malerba; Radosevi, \& Meissner).

Capacidade tecnológica refere-se a um estoque de conhecimento acumulado em pessoas (qualificação formal, conhecimento, experiência e habilidades); sistemas organizacionais (conhecimento acumulado nas rotinas organizacionais, procedimentos, instruções, documentações, técnicas de gestão e processos); sistemas técnico-físicos (máquinas, equipamentos, sistemas de informação e softwares); e produtos e serviços (atividades de desenho, desenvolvimento, prototipagem, teste, produção e comercialização de produtos) (Bell \& Figueiredo, 2012).

O conceito de capacidade tecnológica incorpora a ideia de que sua construção é um processo com caráter de gradação ou continuum de atividades com graus de sofisticação e dificuldade crescentes (Lall, 1992). Portanto, o desenvolvimento tecnológico é gradual e é possível identificar níveis de acumulação de capacidades tecnológicas. Bell e Pavitt (1995) e Lall (1992) identificaram quatro níveis de capacidades: um de capacidade tecnológica 
de produção e três níveis de capacidade tecnológica de inovação (básico, intermediário e avançado). A trajetória de acumulação de capacidades tecnológicas refere-se ao caminho percorrido pela organização ao longo do tempo em termos dos diferentes níveis de capacidades tecnológicas acumuladas.

Para progressão na acumulação de capacidades tecnológicas são necessários engajamentos em processos de aprendizagem. Estes referem-se a processos conscientes, intencionais, custosos, não automáticos, ativos e deliberados, em que habilidades e conhecimentos são adquiridos por indivíduos e pela organização (Bell \& Figueiredo, 2012). Essas aquisições são cumulativas e aumentam o estoque de conhecimento ou as capacidades tecnológicas da empresa (Malerba, 1992). Portanto, os processos de aprendizagem auxiliam na explicação das trajetórias de acumulação de capacidades tecnológicas das empresas (Figueiredo \& Cohen, 2019; Hansen \& Lema, 2019; Hansen \& Ockwell, 2014).

Vários autores elaboraram diversas tipologias de atividades de aprendizagem. Arrow (1962) identificou o learning by doing aprofundado por outros autores, como Dosi, Grazzi, \& Mathew (2017). Urzúa (2013) utilizou outro conjunto de tipologias: "learning by peer interaction, learning by education and training, learning by hiring, learning by taking over, learning by searching knowledge and information, learning by improving, engineering and design, learning by developing and researching."

Os estudos também abordam a interdependência da aprendizagem tecnológica entre as empresas e outras organizações como: empresa e universidade e/ou institutos de pesquisa (Lee \& Miozzo, 2019; Yoruk, 2011); cliente e fornecedores (Figueiredo \& Piana, 2016; Stubrin, 2018; Urzúa, 2003) e redes de conhecimento (Dantas \& Bell, 2011; Tumelero, Sbragia, Borini, \& Franco, 2018). Também há estudos que abordam a interdependência da aprendizagem tecnológica intrafirma, como, por exemplo, entre subsidiárias de multinacionais (empresas irmãs e matriz) (Marin \& Bell, 2010).

No entanto, nas literaturas de gestão da inovação têm dado mais ênfase ao conhecimento adquirido a partir de $P \& D$. Isso parece refletir, em uma ênfase maior por parte dos estudos no entendimento da capacidade de inovação a partir de proxies de patentes e P\&D (Miao, Song, Lee, \& Jin, 2018).

\subsection{MENSURAÇÃO DAS CAPACIDADES TECNOLÓGICAS}

Os indicadores convencionais de mensuração de capacidades tecnológicas estão relacionados à pesquisa e desenvolvimento $(P \& D)$ e patentes. Esses indicadores são úteis pois: apresentam-se como um modelo com característica genérica, permitindo que seja aplicado em diferentes contextos; possibilitam a aplicação de questionários de maneira periódica e contínua, com levantamentos de informação mais rápidos que outras formas 
de mensuração; e esse modelo de mensuração já está replicado e popularizado entre diversos países (Figueiredo, 2001). Porém, são insuficientes em alguns setores industriais de economias emergentes que não apresentam níveis aprofundados de inovação. Logo, a aplicação exclusiva dos indicadores convencionais se torna irrelevante nesse contexto (Bell \& Pavitt, 1993, 1995; Figueiredo, 2001; Lall, 1992).

Diante disso, operacionalizou-se a trajetória de acumulação de capacidade tecnológica por meio de uma abordagem de "capacidade revelada" (Sutton, 2012), o que significa que as capacidades das empresas são reveladas em suas atividades tecnológicas inovadoras. Diante disso, apresentam-se modelos de análise que captam os diferentes graus de atividades inovadoras, e que também levam em consideração indicadores convencionais para compreender o processo de acumulação de capacidades tecnológicas (Figueiredo \& Cohen, 2019; Hansen \& Lema, 2019; Hansen \& Ockwell, 2014). Assim, sugerese para a análise de acumulação das capacidades tecnológicas na indústria leiteira uma estrutura baseada nas capacidades reveladas (Figueiredo \& Cohen, 2019; Figueiredo \& Piana, 2018) (Tabela 1). Essas estruturas demonstram que as capacidades tecnológicas são categorizadas em níveis a partir das atividades realizadas pela empresa. Os níveis de capacidades tecnológicas estão associados com o grau de novidade e complexidade das atividades tecnológicas que as empresas são capazes de desempenhar, ou seja, trata-se de uma mensuração qualitativa.

Tabela 1

Modelo para mensuração das capacidades tecnológicas na indústria leiteira

\begin{tabular}{|c|c|}
\hline $\begin{array}{l}\text { Níveis de } \\
\text { Capacidade } \\
\text { Tecnológica }\end{array}$ & $\begin{array}{l}\text { Exemplos de atividades tecnológicas que representam o nível de Capacidade } \\
\text { Tecnológica }\end{array}$ \\
\hline $\begin{array}{l}\text { Capacidade de } \\
\text { Inovação Avança- } \\
\text { da-Nível } 5\end{array}$ & $\begin{array}{l}\text { Capacidade para implementar atividades inovadoras de natureza similar aos líderes } \\
\text { globais em inovação com grau de novidade mundial. Por exemplo: desenvolvimento de } \\
\text { novos processos de produção baseados em } P \& D \text { (patentes); desenvolvimentos de solu- } \\
\text { ções baseadas em P\&D para problemas específicos; desenvolvimento de novos produtos } \\
\text { baseados em patentes; P\&D em melhoramento de leite e seus subprodutos; desenvol- } \\
\text { vimento de ferramentas e soluções de gestão de alta complexidade; P\&D baseado em } \\
\text { gestão de laticínios e logística de laticínios. }\end{array}$ \\
\hline $\begin{array}{l}\text { Capacidade de } \\
\text { Inovação Interme- } \\
\text { diári-Nível } 4\end{array}$ & $\begin{array}{l}\text { Capacidade para implementar atividades inovadoras de natureza incremental a partir } \\
\text { de mudanças complexas geralmente baseada em engenharia e com grau de novidade } \\
\text { para o País. Por exemplo: desenvolvimento de adaptações em máquinas e equipamen- } \\
\text { tos baseadas em engenharia; desenvolvimento de grandes melhorias no processo de } \\
\text { produção baseadas em engenharia; desenvolvimento de novos processos de produção } \\
\text { com grau de novidade para o estado ou País; desenvolvimento de novos produtos com } \\
\text { grau de novidade para o estado ou País; transferência de especificação de produção/ } \\
\text { produtos oriundos de P\&D; equipes multidisciplinares de desenvolvimento de soluções } \\
\text { inovadoras para gestão de laticínios com grau de novidade para o estado ou País. }\end{array}$ \\
\hline
\end{tabular}




\begin{tabular}{ll}
\hline $\begin{array}{c}\text { Níveis de } \\
\text { Capacidade } \\
\text { Tecnológica }\end{array}$ & \multicolumn{1}{c}{$\begin{array}{c}\text { Exemplos de atividades tecnológicas que representam o nível de Capacidade } \\
\text { Tecnológica }\end{array}$} \\
\hline & $\begin{array}{l}\text { Capacidade para implementar atividades tecnológicas à base de pequenas adaptações } \\
\text { e melhorias de tecnologias existentes com grau de novidade local. Por exemplo: utiliza- } \\
\text { ção de novas técnicas organizacionais para a empresa (JIT-Just in Time, TQC-Total } \\
\text { Quality Control, MRP-Material Requirements Planning, ERP-Enterprise Resource }\end{array}$ \\
$\begin{array}{l}\text { Capacidade de } \\
\text { Inovação Básica- } \\
\text { Nível 3 }\end{array}$ & $\begin{array}{l}\text { Planning), Produção Enxuta, sistemas de manufatura (CIM-Manufatura Auxiliada por } \\
\text { Computador e PCP-Planejamento e Controle da Produção); melhorias de eficiência } \\
\text { baseada na experiência; desenvolvimento de novos produtos com maior grau de com- } \\
\text { plexidade; melhorias das atividades de produção com grau de novidade local ou para a } \\
\text { empresa; melhorias na gestão das atividades da empresa com grau de novidade local } \\
\text { ou para a empresa. }\end{array}$ \\
\hline
\end{tabular}

\begin{tabular}{|c|c|}
\hline $\begin{array}{l}\text { Capacidade de } \\
\text { Produção Avança- } \\
\text { da-Nível } 2\end{array}$ & $\begin{array}{l}\text { Capacidade para usar tecnologias existentes com base em níveis nacionais de eficiência } \\
\text { e qualidade. Por exemplo: avançado planejamento e controle da produção; controle da } \\
\text { qualidade para atendimento às exigências internacionais; formalização das práticas } \\
\text { de gestão; adaptação de produtos ou de especificações de produtos existentes; uso de } \\
\text { ferramentas de gestão de forma rotineira e contínua. }\end{array}$ \\
\hline $\begin{array}{l}\text { Capacidade de } \\
\text { Produção Básica- } \\
\text { Nível } 1\end{array}$ & $\begin{array}{l}\text { Capacidade para usar tecnologias existentes com grau de eficiência e qualidade local. } \\
\text { Por exemplo: controle da qualidade para manter os padrões existentes e exigências } \\
\text { locais; operação rotineira de processo de produção; imprevisibilidade de qualidade e } \\
\text { padronização de produtos; práticas internas de gestão informais, intermitentes e inci- } \\
\text { pientes; oferta de produtos tradicionais locais (exemplo: queijo mussarela); replicação de } \\
\text { produtos seguindo especificações simples; imprevisibilidade de prazos, orçamento, etc. }\end{array}$ \\
\hline & $\begin{array}{l}\text { Explaining early entry into path-creation technological catch-up inthe forestry and } \\
\text { ce from Brazil," by P.N. Figueiredo e M. Cohen, 2019, Research Policy, 48, pp. 1694-1713 e } \\
\text { building and learning linkages in knoledge-intensive servisse SMEs in Brazil's mining } \\
\text { redo e J. Piana, 2018, Resources Policy, 58, pp. 21-23. }\end{array}$ \\
\hline
\end{tabular}

A Tabela 1 apresenta o modelo de mensuração de capacidades tecnológicas na indústria leiteira com exemplos ilustrativos das atividades que expressam os níveis e tipos de capacidade tecnológica, esta última diferenciado em capacidade de produção e capacidade de inovação. A primeira refere-se às capacidades para usar tecnologias existentes com determinados níveis de eficiência, a última significa a habilidade das empresas tanto para assimilar, usar, adaptar e mudar tecnologias existentes quanto para criar novas tecnologias e desenvolver novos produtos e processos (Bell \& Pavitt, 1993, 1995).

Cabe ressaltar que o modelo da Tabela 1 foi adaptado dos modelos originais à indústria leiteira (laticínios) por meio de evidências fornecidas por empresas do setor, professores e pesquisadores da área, além de materiais técnicos sobre a indústria e do conhecimento adquirido pelos pesquisadores com a realização das atividades de campo e de levantamento de dados secundários. Particularmente, foram realizadas entrevistas com laticínios da região Sudoeste do Paraná e com professores da área; entrevistas na agência de desenvolvimento regional do Sudoeste do Paraná; e participação em eventos relacionados à produção leiteira do Sudoeste do Paraná. A mensuração da acumulação de capacidade tecnológica, portanto, baseou-se em atividades que os laticínios desenvolveram ao longo dos anos de operação. 


\section{PROCEDIMENTOS METODOLÓGICOS}

A pesquisa realizou um exame em nível micro para obter uma perspectiva diferenciada, detalhada e dinâmica sobre as trajetórias de acumulação de capacidades tecnológicas e seus processos de aprendizagem em empresas da indústria leiteira (laticínios) do Sudoeste do Paraná. Utilizou-se uma abordagem qualitativa e indutiva. Tal abordagem foi operacionalizada por meio de uma estratégia de pesquisa que utilizou estudos de caso com base em evidências empíricas de primeira mão coletadas por meio de trabalho de campo. Essa abordagem metodológica é apropriada para gerar uma melhor compreensão do que está por trás de um fenômeno sutil e pouco pesquisado, captando detalhes e nuances que não poderiam ser capturados por outras técnicas, como a análise agregada derivada de métodos puramente quantitativos (Yin, 2009).

A justificativa para a seleção dos casos envolveu uma escolha intencional de organizações (Miles \& Huberman, 1994). De acordo com Patton (2002), a lógica e poder de amostragem proposital/intencional reside na seleção de casos ricos em informação para um estudo em profundidade. Inicialmente a seleção das empresas do estudo foi realizada por meio de consultas com especialistas e bancos de dados da indústria. A partir do mapeamento das empresas consideradas relevantes para o estudo, entrou-se em contato para participação da pesquisa. Foram selecionados quatro laticínios para a pesquisa final. A escolha por um número pequeno de casos, segundo Yin (2009), é válida quando o pesquisador está interessado em observar o comportamento de um fenômeno ao longo do tempo. $O$ autor afirma que não há um número mínimo de casos requeridos, o mais importante é buscar casos ricos que representem o fenômeno a ser investigado.

Quanto ao processo de coleta de dados, para realizar a reconstrução da trajetória de acumulação de capacidades tecnológicas das empresas, foram demandadas informações sobre as atividades de produção e inovação desenvolvidas pelas empresas, em termos de: "quando iniciou"; "por quêe"; "como foi feito"; e "quem realizou". Já para o exame dos processos de aprendizagem foram levantadas evidências para identificação e caracterização dos mecanismos de aprendizagem. Para captar características dos mecanismos de aprendizagem, foram buscadas evidências de "por quê", "quem", "como" e "quando" ocorreram os usos dos mecanismos. As técnicas de coleta de dados foram observações por meio de visitas às instalações, consulta a documentos, encontros informais e entrevistas semiestruturadas. As entrevistas duraram aproximadamente entre duas e quatro horas e foram realizadas com sócios, gerentes, engenheiros e técnicos. A escolha dos sujeitos entrevistados foi orientada pelo principal responsável da empresa, que indicou fontes ricas de informação sobre o tema dentro da empresa e fora dela (como distribuidores e produtores de leite). No que tange ao processo de análise, seguindo Miles e Huberman (1994), este foi iniciado durante o 
trabalho de campo e envolveu atividades como: transcrições das entrevistas e as principais interpretações por parte dos investigadores; organização das evidências por empresas; e marcações nas transcrições de entrevistas para destacar evidências. Foram criadas matrizes de dados para cada organização com as principais evidências extraídas do trabalho de campo relacionadas às atividades inovadoras e aos processos de aprendizagem. Um passo importante nesse processo analítico refere-se ao envolvimento de rodadas recursivas de interpretações da matriz de dados, com consultas da literatura. Foi durante esse processo analítico que os primeiros desenhos das trajetórias de acumulação de capacidades tecnológicas começaram a emergir. As características das trajetórias foram associadas com os processos de aprendizagem (mecanismos de aprendizagem). Finalmente, foram criadas pequenas narrativas a partir de esboços. $O$ desenvolvimento de esboços em narrativas curtas ajudou a estabelecer relações e fortalecer os argumentos (Dougherty, 2002). As narrativas foram a base para a construção dos resultados.

\section{RESULTADOS}

Esta seção apresenta as trajetórias de acumulação de capacidades tecnológicas dos quatro laticínios investigados (aqui denominados Beta, Gama, Kappa e Alpha). Além disso, expressam-se os principais processos de aprendizagem (mecanismos de aprendizagem) utilizados pelas empresas.

\subsection{TRAJETÓRIA DE ACUMULAÇÃO DE CAPACIDADES TECNOLÓGICAS: ESTAGNAÇÃO EM PRODUÇÃO BÁSICA}

A pesquisa revelou que três laticínios analisados (Beta, Gama e Kappa) obtiveram trajetórias de acumulação de capacidades tecnológicas muito similares; mesmo com variações no período de surgimento dos laticínios, estes apresentaram uma trajetória de estagnação em capacidade de produção básica (Nível 1).

\subsubsection{Trajetória de acumulação de capacidades tecnológicas: $O$ caso do Laticínio Beta}

O Laticínio Beta é uma organização iniciada na década de 1990 na região Sudoeste do Paraná. Em 2017 gerava cerca de 110 empregos diretos, processando 135.000 litros de leite por dia, os quais produzem aproximadamente 400 toneladas de queijos por mês. $O$ laticínio é um empreendimento formado por 16 sócios da comunidade local. 
Laticínio Beta iniciou suas atividades em uma escola desativada em meados dos anos 1990. A motivação para a criação do laticínio surgiu em razão do fato de na época existir apenas uma empresa captadora de leite na cidade e, também, de uma visita técnica à região de Emilia-Romana (Itália), realizada pelo prefeito e vereador (atual gerente administrativo do laticínio) da cidade. A visita gerou informações que poderiam proporcionar um caminho alternativo para a economia local, pois em ambas as regiões (Sudoeste do Paraná e EmiliaRomana) o processo produtivo ocorria por pequenas cooperativas familiares, aspecto ressaltado pelo técnico agropecuário: "Então surgiu a ideia, se nós vamos juntar leite, por que não fabricar? Vender o produto processado, e aí apareceu a ideia do Pacto Nova Itália". (Informação verbal, 31 de maio de 2017).

O Programa Pacto Nova Itália trouxe mudanças ao modelo produtivo agrícola, pois em meados dos anos 1990, o Sudoeste do Paraná passava por uma depressão econômica e social. O objetivo do programa era agregar valor aos produtos, pela transformação da matéria-prima produzida na região (leite).

Incorporado ao Programa Pacto Nova Itália, o laticínio iniciou suas atividades com 23 sócios e captando 623 litros de leite por dia oriundos dos próprios sócios. Nos meses seguintes, outros produtores de leite da comunidade local também passaram a entregar seu leite produzido para o novo laticínio. Diante disso, após o primeiro ano de funcionamento - laticínio passou pela sua primeira ampliação. O EMATER, PR participou na elaboração do projeto. A Administração Municipal ajudou na adaptação do prédio, nas instalações elétricas e no calçamento. A Associação de Produtores fez financiamentos por meio da linha PRONAFAGREGAR, para pagamento em oito anos. O Programa Paraná Doze Meses ajudou a entidade mediante de projetos a fundo perdido.

Nesse mesmo período, o laticínio, em termos de processos de aprendizagem, recebeu assistência técnica de agrônomos, coordenadores das Associações Municipais, representantes do Sindicado dos Trabalhadores Rurais e do Centro de Apoio ao Pequeno Agricultor (CAPA), orientando os associados sobre a viabilidade do trabalho em associações. O leite, que já era fonte de renda de muitos produtores e não muito valorizado, passou a ser assunto recorrente nas reuniões das entidades supracitadas. $O$ interesse por formação de pastagens específicas para gado leiteiro era o assunto de maior interesse do grupo, que desenvolveu trabalhos práticos em algumas propriedades.

Os produtos iniciais do laticínio eram o queijo mussarela, queijo parmesão e trançados temperados, desenvolvidos por meio de replicação de produtos seguindo especificações simples. Os anos 2000 iniciaram com uma boa aceitação dos produtos no mercado e percebeu-se a procura cada vez maior por estes. Diante disso, os produtores, incentivados pelo programa Bom Pasto da Secretaria Municipal de Agricultura, buscaram iniciativas para aumentar a produção leiteira, com a qualidade. Foi inserido o queijo prato. 
Em 2008 houve um aumento de 30\% da capacidade de produção, haviam 1.000 produtores de leite e 75 funcionários. Em termos de processos de aprendizagem, nos anos 2000 a empresa passou a realizar vários treinamentos internos e contava com a assistência técnica de fornecedores de equipamentos. Portanto, no período entre os anos 1990 e 2000, - laticínio Beta apresentava nível de capacidade tecnológica de produção básica (Nível 1)-capacidade para usar tecnologias existentes com grau de eficiência e qualidade local.

Em 2013, o laticínio processava cerca de 100.000 litros de leite por dia, contando com 100 colaboradores. Em 2014 houve um aumento de 20\% no número de empregos diretos e os produtos fabricados eram mussarela (carro-chefe), provolone, creme de leite, manteiga, queijo colonial e soro concentrado. Ademais, a quantidade de leite recebido exigiu um novo investimento, dessa forma, foi montada uma nova fábrica, com capacidade de processamento de 250.000 litros de leite por dia. Sobre a nova fábrica, o Gerente Administrativo destacou:

Quando começamos com a nova fábrica era para ser tudo automatizado. Mas esse processo com esses equipamentos novos não estava dando qualidade. Para ter qualidade acabava com a nossa renda. Nós temos um consumidor muito fiel, que estava acostumado com uma qualidade, e quando a gente colocou aquele equipamento todo automatizado a nossa qualidade quase que foi para o ralo. Era só cliente reclamando. (Informação verbal, 31 de maio de 2017).

O Gerente Administrativo destaca os vários processos de aprendizagem utilizados, que buscavam sanar os problemas produtivos da nova fábrica.

\footnotetext{
Nós tentamos, assistência técnica das empresas de fermento, da empresa que forneceu o equipamento. Mas eles não têm técnico que está no dia a dia dentro da fábrica. $O$ técnico do equipamento sabe do funcionamento da máquina, mas não do processo. Nós recorremos às empresas que fornecem fermento, e toda semana vinha um novo técnico para tentar acertar, e nada. Inclusive, trouxemos um engenheiro que trabalha em um grande laticínio em Goiás, ficou vários dias e não conseguiu. Tudo no processo é tempo e temperatura que envolve vários detalhes e não conseguimos levar isso para a fábrica maior. O queijo começava a descamar tipo um peixe, não tinha jeito. Tivemos que sacar o equipamento de mais de 1 milhão e voltamos manualmente, e o negócio engrenou. (Informação verbal, 31 de maio de 2017).
}

Em termos de processos de aprendizagem, além da assistência técnica, o laticínio passou a realizar treinamentos no Sebrae, em razão da dificuldade da empresa em utilizar o software de gestão do laticínio. Segundo o Gerente Administrativo:

Nós temos um software, mas a gente utilizava muito pouco. Fazemos controle em planilhas do Excel. Isso é ruim, porque se você perde um funcionário, você perde muitos dados. Se você tem 
um sistema, está tudo ali, qualquer um que vem pode consultar. Então a gente está usando muito pouco do sistema, então, o treinamento do Sebrae veio para ajudar a gente a usar mais o sistema. (Informação verbal, 31 de maio de 2017).

Portanto, apesar dos investimentos observados, o laticínio ainda carece de controles de qualidade automatizados que atendam às exigências nacionais e internacionais, e avançadas práticas de planejamento e controle, caracterizando a manutenção das capacidades de produção básica (Nível 1). A Figura 1 apresenta a trajetória de acumulação de capacidades tecnológicas, destacando as principais atividades que demonstram a capacidade acumulada e os processos de aprendizagem (mecanismos de aprendizagem) envolvidos:

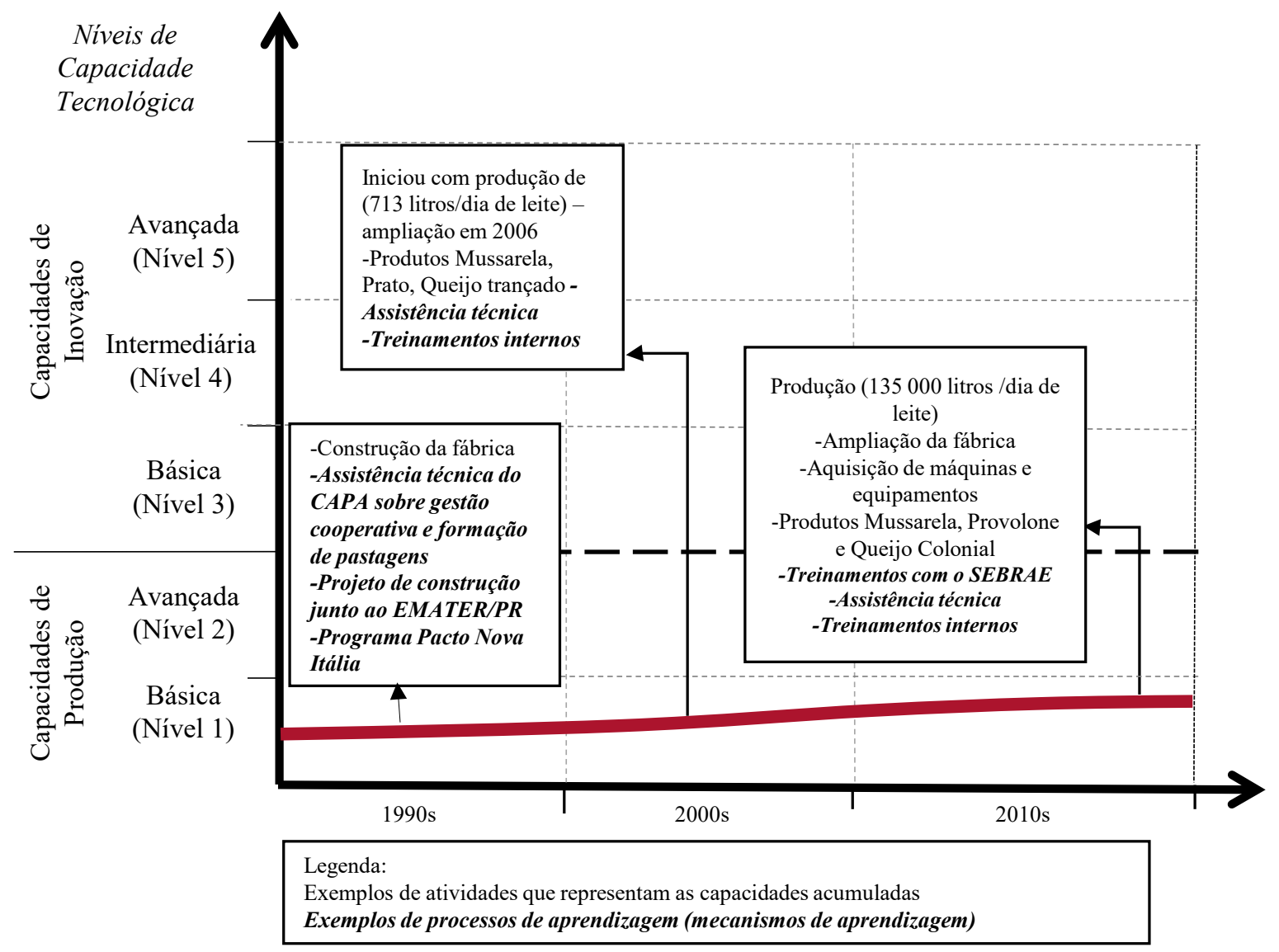

Figura 1. Trajetória de acumulação de capacidades tecnológicas do Laticínio Beta.

\subsubsection{Trajetória de acumulação de capacidades tecnológicas: $O$ caso do Laticínio Gama}

O Laticínio Gama é uma empresa familiar que iniciou suas atividades em 2007 na região Sudoeste do Paraná. Em 2017 processava cerca de 30.000 litros de leite, oferecendo principalmente queijo Mussarela e contando com aproximadamente 130 produtores. 
No período anterior a 2007, o Laticínio Gama era uma associação pequena. A associação não teve êxito em razão da dificuldade no processo de produção do queijo e desentendimentos entre os associados. O local ficou fechado por um ano, até que o Laticínio Gama adquiriu as instalações. De acordo com o proprietário:

\begin{abstract}
A partir de julho fomos liberados para começar a fabricar na época o queijo mussarela, o queijo prato, a ricota e o minas, já com o Serviço de Inspeção Federal (SIF), oportunizando que lançássemos os produtos para todo o País. Então começamos pequenos, 600 litros por dia e $75 \mathrm{~kg}$ de queijo por dia. E fomos montando as linhas, a logística, a conquistar matéria-prima que é o leite, e hoje vendemos só no Paraná. (Informação verbal, 14 de setembro de 2017).
\end{abstract}

A partir dos anos 2010, o laticínio passou a processar 30.000 litros de leite. Diante disso, o proprietário destacou as dificuldades de conseguir produtores da matéria-prima, visto a chegada de grandes empresas: "nós pegamos pequenos produtores que estavam com dificuldades e estamos investindo, fazendo seminários e visitas técnicas." (Informação verbal, 14 de setembro de 2017).

Ademais, o proprietário destaca que houve muitas mudanças no laticínio após o terceiro ano de funcionamento deste:

\footnotetext{
Nós investimos na parte de maquinário e também muito em qualidade. Nosso queijo é muito bom, é um queijo que não volta, não tem devolução, vários produtos nunca dão problema. Temos um queijeiro extremamente competente e damos muita ênfase à higiene. Conseguimos agregar um preço maior pela qualidade do nosso queijo. Claro que agora podemos ver uma queda na proteína do leite, mas isso tem muito a ver com a pastagem, o clima. (Informação verbal, 14 de setembro de 2017).
}

O Gerente de Produção (queijeiro) já possuía mais de 15 anos de experiência em outros laticínios. Além do gerente, o laticínio possui mais 24 colaboradores. Em termos de processos de aprendizagem são realizados treinamentos internos, especialmente durante a contratação de um novo colaborador, treinamentos com o Senai e Sebrae. O proprietário também destacou as reuniões internas como um mecanismo de aprendizagem: "são feitas reuniões e é tudo registrado, quem participa assina, fica tudo arquivado e é repassado aos outros." (Informação verbal, 14 de setembro de 2017).

Portanto, diante do exposto, desde o início das suas atividades em 2007 o laticínio ainda tem um foco local no desenvolvimento de suas atividades, apresentando um nível de capacidade tecnológica de produção básica (Nível 1)-capacidade para usar tecnologias existentes com grau de eficiência e qualidade local. A Figura 2 apresenta a trajetória de acumulação de capacidades tecnológicas, destacando as principais atividades que 
demonstram a capacidade acumulada e os processos de aprendizagem (mecanismos de aprendizagem) envolvidos:

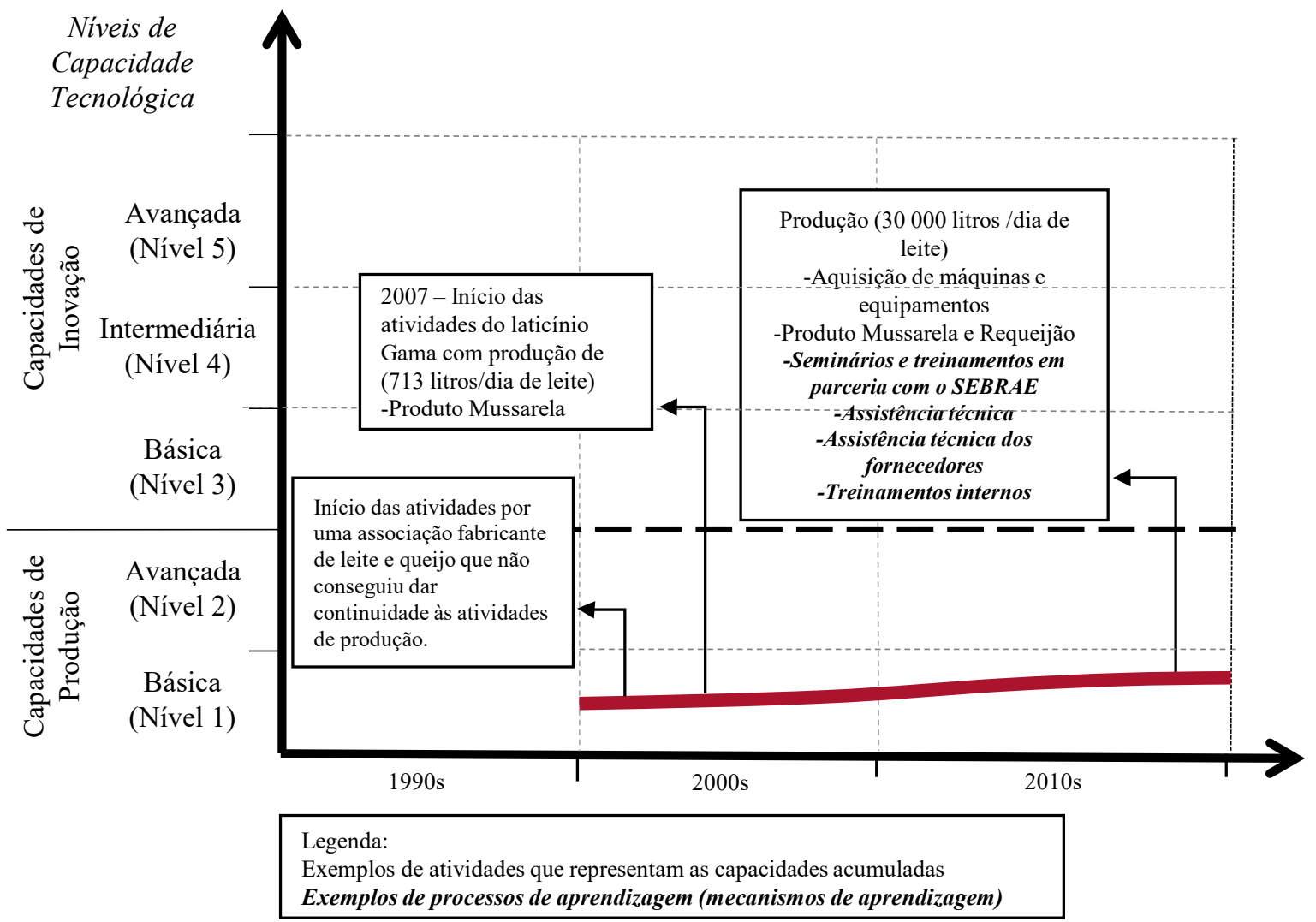

Figura 2. Trajetória de acumulação de capacidades tecnológicas do laticínio Gama.

\subsubsection{Trajetória de acumulação de capacidades tecnológicas: $O$ caso do Laticínio Kappa}

O Laticínio Kappa iniciou suas atividades no ano de 1998. Em 2017 possuía 300 produtores de leite e processava cerca de 70.000 litros de leite por dia. Os produtos ofertados ao mercado eram o queijo mussarela (carro-chefe) e o queijo provolone. Sobre processos de aprendizagem eram realizados treinamentos internos e em parceria com fornecedores. De acordo com o Analista Administrativo:

Os fornecedores de produtos químicos, por exemplo, já vieram dar treinamento para os colaboradores, de equipamentos em si não. Dai tem o responsável pela manutenção, que faz treinamento interno com os colaboradores. Questões de utilização de Equipamentos de Proteção Individual (EPIs) fazemos com uma empresa terceirizada. (Informação verbal, 12 de maio de 2017). 
O Analista ressaltou que são realizados treinamentos em média três vezes por ano e que com as universidades são realizadas parcerias de estágios com a Unipar e a UTFPR. Também são realizados treinamentos com os transportadores de leite, três vezes por ano, em questões de qualidade.

Em termos de mudanças de processos, o Analista ressalta que não houve grandes adaptações. A principal mudança foi a ampliação da empresa e a aquisição de alguns equipamentos por volta de cinco anos atrás. De acordo com o Analista, "inseriu-se pavimentação, na estruturação da fábrica, e não teve muitas alterações, nem no fluxo de produção, foi mais na parte de fora mesmo." (Informação verbal, 12 de maio de 2017). Em termos de gestão de planejamento e controle, essas atividades são realizadas em planilhas Excel.

Com relação ao produto, no passado havia maior variedade, porém, desde meados dos anos 2000, optou-se por trabalhar apenas com o queijo mussarela, o queijo tipo provolone e os subprodutos creme e soro. $O$ queijo mussarela representa mais de $50 \%$ do faturamento. O Analista destacou o processo produtivo do queijo:

A gente pega fermento importado da Cristi Hansel. E o nosso provolone é tipo provolone, ele é a mesma massa do mussarela, só que ele fica em um tanque de fumaça líquida, e a enformagem dele é diferente, ela é redonda e ele fica em fumaça. Ele fica um dia a mais na fumaça líquida, comparado ao mussarela. (Informação verbal, 12 de maio de 2017).

Sobre qualidade, o Analista ressalta que "há um monitoramento constante junto aos colaboradores, uma verificação diária se eles estão cumprindo com as normas da empresa, como boas práticas de higienização, tanto pessoal quanto de equipamentos e utensílios." (Informação verbal, 12 de maio de 2017). Porém, algumas vezes são encontrados problemas nos produtos "na matéria-prima não, mas às vezes o queijo está um pouco mole, a gente sempre está verificando, pois acontecem essas falhas no processo de produção." (Informação verbal, 12 de maio de 2017).

Portanto, diante do exposto, desde 1998 o laticínio apresenta um nível de capacidade tecnológica de produção básica (Nível 1)-capacidade para usar tecnologias existentes com grau de eficiência e qualidade local. A Figura 3 apresenta a trajetória de acumulação de capacidades tecnológicas, destacando as principais atividades que demonstram a capacidade acumulada e os processos de aprendizagem (mecanismos de aprendizagem) envolvidos: 


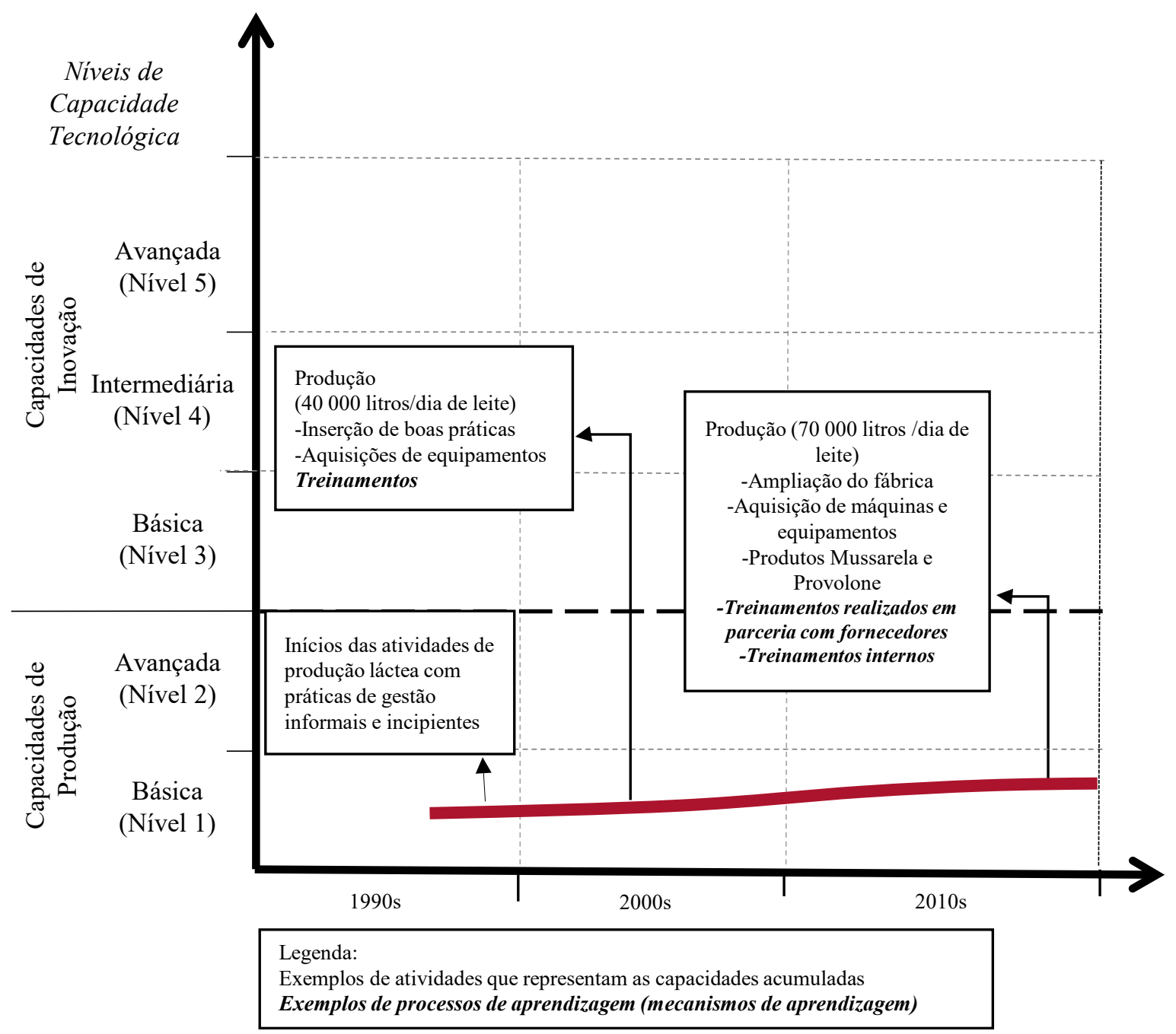

Figura 3. Trajetória de acumulação de capacidades tecnológicas do Laticínio Kappa.

\subsection{TRAJETÓRIA DE ACUMULAÇÃO DE CAPACIDADES TECNOLÓGICAS: DE PRODUÇÃO BÁSICA À CAPACIDADE DE INOVAÇÃO INTERMEDIÁRIA}

O Laticínio Alpha é uma empresa familiar fundada em 1996 na região Sudoeste do Paraná. Em 2017 a empresa apresentava capacidade produtiva de 230 mil litros por dia e possuía mais de 1.000 produtores cadastrados. $O$ principal produto é o queijo mussarela. 


\subsubsection{Anos 1990: Acumulação de capacidades tecnológicas de produção básica}

Nos anos 1980 o local atual das instalações do Laticínio Alpha pertencia a um abatedouro. Nesse período, o proprietário do abatedouro percebeu a oportunidade de mercado para a abertura de um pequeno laticínio. Segundo o Gerente de Captação e Qualidade, "naquela época não era tão complicado abrir um laticínio, não havia tanta cobrança." (Informação verbal, 8 de maio de 2017).

Porém, o pequeno laticínio passou por problemas financeiros e foi adquirido, nos anos 1990, pelo atual proprietário do Laticínio Alpha, que na época administrava um mercado na mesma cidade. Em 1996 o laticínio processava 3.000 litros por dia de leite, mas o novo proprietário, pela sua experiência de mercado, especialmente no varejo, vislumbrava oportunidades de crescimento no futuro.

O foco na década de 1990 esteve sob o entendimento do funcionamento do negócio e na manutenção das atividades de produção láctea, mantendo os padrões locais de exigência de qualidade e com práticas de gestão informais e incipientes. $O$ único produto era o queijo mussarela. Portanto, nesse período o Laticínio Alpha apresentava nível de capacidade tecnológica de produção básica (Nível 1)-capacidade para usar tecnologias existentes com grau de eficiência e qualidade local.

\subsubsection{Anos 2000: Acumulação de capacidades tecnológicas de produção avançada}

No início dos anos 2000 o laticínio passou a processar 40.000 litros por dia de leite. Segundo o Gerente de Captação e Qualidade,

\footnotetext{
laticínios você mede pela quantidade de leite que ele processa, se você quer saber o porte de uma empresa, nesse ramo, você não vê a quantidade de funcionários, nada, você vê a quantidade industrializada, e em 2005 o laticínio processava entre 40.000 e 50.000 litros. (Informação verbal, 8 de maio de 2017).
}

Também, segundo o Gerente de Captação e Qualidade, "nos anos 2000 foi quando começaram a investir no negócio, o laticínio foi crescendo porque os donos não precisavam tirar recursos do laticínio para eles, tudo era reinvestido no próprio laticínio." (Informação verbal, 8 de maio de 2017). Assim, foram feitas várias aquisições de equipamentos acompanhadas 
de contratos de assistência técnica que posteriormente auxiliaram os colaboradores na manutenção destes.

Nesse período, por meio de replicação de produtos seguindo especificações simples, a empresa passou a produzir o queijo provolone e o parmesão. Também, com o aumento dos investimentos e da capacidade produtiva, a empresa passou a formalizar práticas de gestão voltadas ao planejamento e controle da produção. Ainda, passou a incorporar controles de qualidade que atendessem às exigências nacionais, visto a necessidade de ampliação do mercado, caracterizando, nesse período, a capacidade tecnológica de produção avançada (Nível 2).

\subsubsection{Anos 2010: Acumulação de capacidades tecnológicas de inovação básica e intermediária}

Entre 2010 e 2014 o Laticínio Alpha cresceu entre 25\% e 30\% (em processamento de leite) por ano. Em 2017 processava 230.000 litros por dia. Segundo o Gerente de Captação e Qualidade, o crescimento da empresa esteve atrelado ao próprio crescimento da indústria no período:

Em 2005 começou a melhorar o poder aquisitivo da população brasileira. Por consequência, aumentou o consumo de litros de leite per capita. Até 2005 o brasileiro consumia 15 litros. Em 2010, o consumo era 110 litros. Também, surgiram novas tecnologias no mercado, que ajudaram nos nossos produtos, que sugaram um pouco desse produto, e consequentemente as empresas que ficaram atentas a esse nicho de mercado conseguiram crescer. (Informação verbal, 8 de maio de 2017).

De acordo com o Gerente de Captação e Qualidade, para acompanhar o crescimento da indústria as principais mudanças realizadas pela empresa foram balizadas na compra de novos equipamentos e matérias-primas ofertados pelos fornecedores: "Todo o ano qualquer empresa do nosso ramo precisa se renovar, ou em maquinário, ou em novos produtos, ou em novas tecnologias, alguma coisa você tem que estar mudando para sobreviver." (Informação verbal, 8 de maio de 2017).

Uma das mudanças apontadas pelo Gerente foi a incorporação de um novo fermento para a produção de queijos, importado do Canadá:

Nós temos um fermento que só nós que utilizamos, importado do Canadá, extremamente caro, utilizamos ele porque ele trabalha com toda tecnologia de coagulação, de filagem. E mesmo pagando caro esse produto, o resultado final dele, no nosso processo de produção é muito positivo. Temos um produto de altíssima qualidade, e ainda garantimos o lucro. (Informação verbal, 8 de maio de 2017) 
Ademais, o Gerente destacou o processo de fabricação do queijo desenvolvido pela empresa, exemplificando a capacidade tecnológica de inovação básica da empresa (Nível 3):

Nosso processo tem diferencial. Nós montamos o nosso processo. A matéria-prima vai para um silo de armazenamento, entra na fábrica, e é pasteurizada. Recebe os condimentos, fermento, coalho, os produtos que vão fazer a massa filar. Vai para uma máquina que vai moldar o nosso produto, com uma umidade de $44 \%$. Segue para a salmoura com tanque de gelo para segurar essa umidade. $O$ processo precisou passar por diversos ajustes e melhorias para nos dar qualidade e rendimento industrial. As mudanças nos equipamentos também ajudaram bastante, hoje ele é Tetra Pak. (Informação verbal, 8 de maio de 2017).

O Gerente também destaca que a empresa trabalha com uma visão aberta para mudanças e melhorias:

\begin{abstract}
Apesar de uma estrutura pequena, nós trabalhos com muita tecnologia. Começa com o produto que nós utilizamos, até nosso processo de entrega, é muito bem desenhadinho, é muito bem encaixadinho, a gente segue um roteiro. $E$ no meio de todo esse processo, toda vez que a gente observa uma coisa que a gente possa mudar, possa ganhar, possa ter competitividade industrial, a gente está atento a isso. (Informação verbal, 8 de maio de 2017).
\end{abstract}

Como exemplo de uma visão atenta às melhorias e mudanças, o Gerente destacou o estudo sobre a incorporação de frota própria, o que demonstra a capacidade de inovação básica da empresa (Nível 3):

\begin{abstract}
A questão da frota própria tem um estudo aqui dentro da empresa que a gente fez no passado. A equipe estudou a comparação entre frota própria e de terceiros durante oito meses. Com frota de terceiros, a gente tinha um rendimento industrial anual de 9,5, ou seja, nós precisamos de 9,5 litros de leite para fazer um quilo de produto final adequado. Com frota própria hoje nós trabalhamos com 9,2, e a qualidade do nosso produto melhorou muito. (Informação verbal, 8 de maio de 2017).
\end{abstract}

Portanto, em termos de implicação, essa atividade inovadora gerou a redução do consumo de matéria-prima e a produção de um produto final com qualidade superior.

As melhorias conquistadas pela empresa estão relacionadas com os mecanismos de aprendizagem: treinamento com os colaboradores e contratação de expertise. De acordo com o Gerente: 
Nós determinamos o leite, é o nosso funcionário, não é um terceiro, nossa equipe é parte integrante do negócio. Investimos em mão de obra e capacitação muito forte, foi feito isso no passado, e a gente está tendo muitos resultados positivos com isso. Com relação ao investimento em mão de obra, por exemplo, trouxemos um funcionário que trabalhava na Nestlè para cá. E nós fizemos esse tipo de contratação no leite, na logística, na área industrial e na área de manutenção, que é um dos gargalos do negócio. Então a empresa é muito bem servida de profissionais. (Informação verbal, 8 de maio de 2017).

As atividades de contratação de expertise iniciaram a partir de 2010; de acordo com - Gerente, "a empresa começou a investir em pessoas, a empresa diminuiu a sua margem de lucro, investiu para isso, e hoje colhe os resultados." (Informação verbal, 8 de maio de 2017).

O Gerente também destacou as dificuldades e questionamentos no processo de decisão sobre a criação de uma nova fábrica. Porém, destacou que para se manter na indústria leiteira, que entra em uma fase de maturidade, é preciso crescer, exemplificando a necessidade de manutenção da capacidade tecnológica de produção avançada (Nível 2):

Sobre a nova fábrica, foi uma decisão difícil, mas precisamos crescer. A empresa chegou um ponto que do jeito que ela está organizada e planejada para o futuro ela vai ter um ganho ideal no mercado com muita segurança, ao contrário de muitas empresas médias e pequenas desse segmento, que provavelmente abandonarão a atividade durante os próximos 10 anos. Essa é a nossa avaliação. Tudo que se faz em laticínios se faz em longo prazo, não adianta pensar daqui 30, 40, 60 dias que não conseguem avançar. (Informação verbal, 8 de maio de 2017).

Sobre os equipamentos da nova fábrica, o Gerente destacou o desenvolvimento conjunto de equipamentos entre o Laticínio e os fornecedores estrangeiros, demonstrando a capacidade tecnológica de inovação intermediária (Nível 4):

$80 \%$ do problema de uma empresa que aumenta sua capacidade industrial é que se perde muito em rendimento industrial, porque a tecnologia é algo meio complexo de se falar. Então, a gente trouxe essa equipe de fora, eles vieram, acompanharam nosso processo e desenvolvemos em conjunto os equipamentos para nos atender da melhor maneira. (Informação verbal, 8 de maio de 2017).

O desenvolvimento conjunto baseado em engenharia demonstra o processo de aprendizagem envolvido:

Nós temos um dos melhores gerentes industriais do ramo de queijos do País. Ele, com a equipe da empresa italiana, desenvolveu os equipamentos. A equipe ficou 90 dias aqui dentro da empresa com ele, acompanhando nosso processo e fazendo uma máquina do jeito que a gente pediu. $A$ 
gente quer processar o dobro com o mesmo rendimento que temos hoje, sem perder nada, em uma escala muito maior. (Informação verbal, 8 de maio de 2017).

Em termos de aprendizagem, outro mecanismo muito utilizado é a assistência técnica realizada pelos fornecedores que possuem técnicos atuando no Brasil. Ressalta-se que no Paraná e no Brasil são escassas as empresas de máquinas e equipamentos para laticínios, mesmo sendo uma das regiões com maior produção. De acordo com o Gerente:

a empresa fornecedora de equipamentos mais próxima da gente é a Globoinox no Rio Grande do Sul. Se não é de São Paulo, Minas e Goiás. E não é tudo, dentro das nossas necessidades temos que nos virar com as empresas de fora. (Informação verbal, 8 de maio de 2017).

Outro exemplo de atividade inovadora que demonstra a capacidade tecnológica de inovação intermediária (Nível 4) foi o desenvolvimento conjunto com o fornecedor TOTVS de um software específico para laticínios. De acordo com o Gerente:

Nós somos uma das poucas empresas que desenvolvemos um programa junto com a TOTVS, específico para laticínios. Utilizamos aqui em nosso laticínio, e toda vez que eles vendem esse programa para outra empresa, eles precisam pagar royalties para a gente. Mapeamos desde $\circ$ produtor até o produto final, então se a gente precisar fazer um recall, a gente consegue saber de onde ele veio, qual a temperatura e tudo. Um colaborador rabiscou o programa no passado e eu vim e unifiquei ele. (Informação verbal, 8 de maio de 2017).

Sobre os produtos, nesse período foram inseridos o queijo montanhês e o queijo prato, além dos subprodutos creme, manteiga e concentrado de soro. Também está sendo desenvolvido o processo para a produção de requeijão. $O$ Gerente destacou o processo de aprendizagem via visitas técnicas a competidores: "Têm sido muito natural as visitas entre empresas para conhecer o processo de produção uma da outra. Por exemplo, para desenvolver nosso requeijão, estamos fazendo visitas nas melhores empresas produtoras de requeijão." (Informação verbal, 8 de maio de 2017).

Outros processos de aprendizagem subsidiados pela empresa são a participação em eventos, como Interleite, palestras e cursos. O Gerente destacou:

Os técnicos de captação vão aos shows rurais, vai ter um seminário que vai durar três dias. Nós também recebemos pessoas para fazer estágios. E não é só na minha área, o pessoal no financeiro, por exemplo, está sempre fazendo cursos. A gente também viaja para fora do País, em feiras, em empresas que produzem equipamentos. (Informação verbal, 8 de maio de 2017). 
Portanto, no período de 2010 a 2017 a empresa avança de capacidades tecnológicas de produção avançada (Nível 2) para capacidade de inovação intermediária (Nível 4). A Figura 4 apresenta a trajetória de acumulação de capacidades tecnológicas, destacando as principais atividades que demonstram a capacidade acumulada e os processos de aprendizagem (mecanismos de aprendizagem) envolvidos:

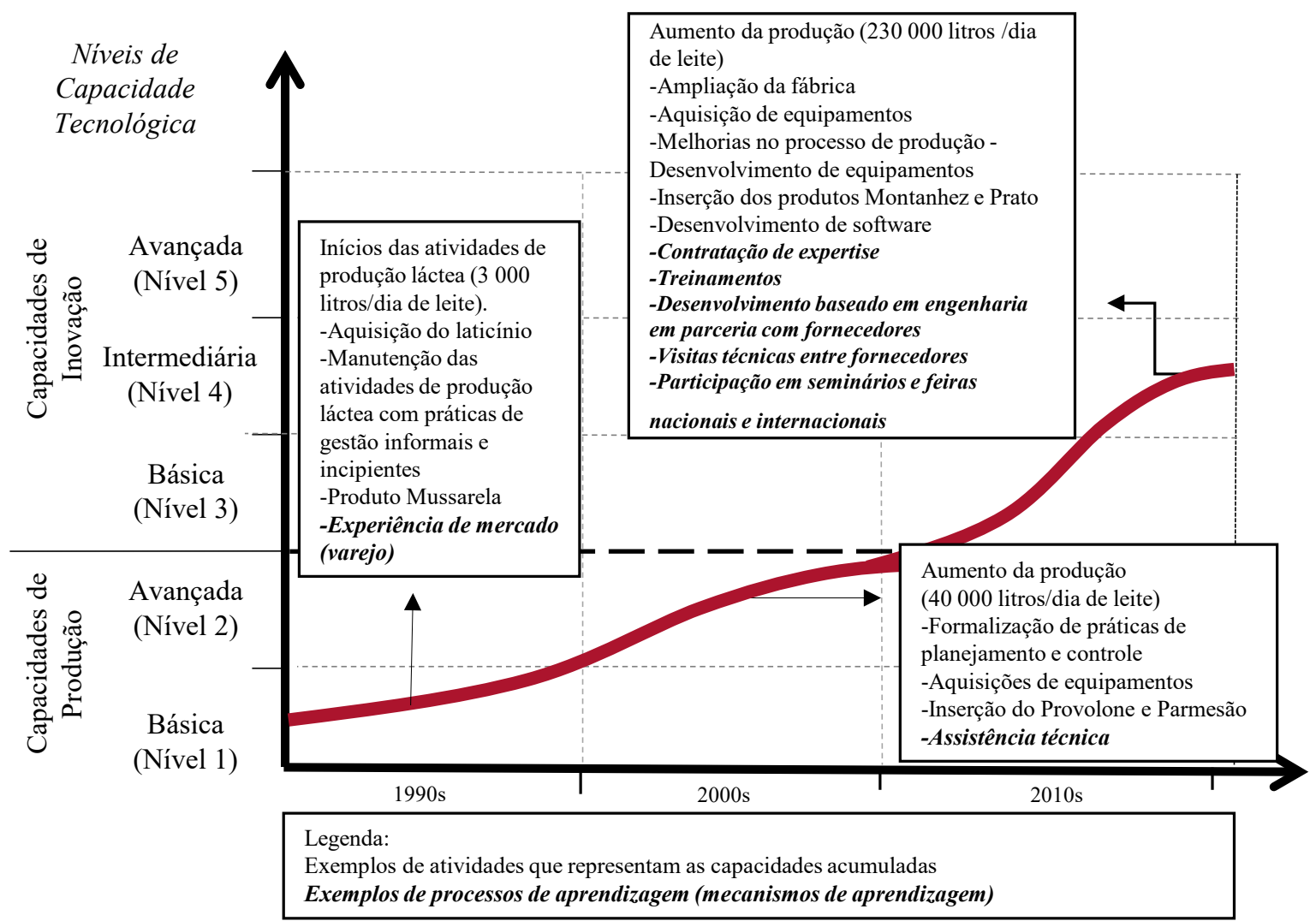

Figura 4. Trajetória de acumulação de capacidades tecnológicas do Laticínio Alpha.

\section{DISCUSSÃO DOS RESULTADOS}

A pesquisa objetivou analisar as trajetórias de acumulação de capacidades tecnológicas e os processos de aprendizagem desenvolvidos por empresas da indústria leiteira do Sudoeste do Paraná.

Diante disso, evidenciaram-se duas trajetórias tecnológicas. A primeira, encontrada no Laticínio Alpha, inicia com capacidade de produção básica, e de maneira contínua avança até capacidade de inovação intermediária. Na segunda trajetória, evidenciada em três laticínios (Beta, Gama e Kappa), as capacidades tecnológicas permanecem estagnadas em produção básica, duas delas por mais de 30 anos. Ademais, reconhece-se que o acúmulo de capacidades tecnológicas está pautado em processos, observando-se poucos movimentos de diversificação de produto-nas duas trajetórias. 
Em termos de processos de aprendizagem, o Laticínio Alpha explorou uma gama de mecanismos de aprendizagem incluindo: treinamentos, assistência técnica, participação em feiras e seminários nacionais e internacionais, visitas técnicas, contratação de expertise e desenvolvimento baseado em engenharia em conjunto com fornecedores. Já os Laticínios Beta, Gama e Kappa utilizaram mecanismos de aprendizagem baseados em treinamento e assistência técnica. Diante disso, parte das variações das trajetórias pode ser explicada pelos processos de aprendizagem utilizados. Em outras palavras, diferentes mecanismos de aprendizagem se associaram às distintas trajetórias de acumulação de capacidades tecnológicas, e resultados similares também foram encontrados em estudos como os de Figueiredo e Piana (2018). Portanto, os mecanismos de aprendizagem treinamento e assistência técnica, quando usados de forma exclusiva, demonstraram-se insuficientes para o desenvolvimento de capacidades de inovação.

\section{CONSIDERAÇÕES FINAIS}

As conclusões oriundas do atendimento ao objetivo da pesquisa que versou sobre a análise das trajetórias de acumulação de capacidades tecnológicas e os processos de aprendizagem desenvolvidos por empresas da indústria leiteira do Sudoeste do Paraná apontam para questões que devem ser consideradas na análise de políticas públicas para a inovação e de tomada de decisões para estratégias empresariais. Em termos de políticas públicas, recomenda-se maior sensibilidade na percepção de que as capacidades tecnológicas em termos de empresa são uma variável importante a ser considerada na concepção da agenda das políticas. Nesse sentido, as iniciativas políticas que visam ao avanço da inovação precisam ser sensíveis às capacidades já acumuladas ao nível das empresas e aos tipos de insumos de conhecimento demandados. Também, sugere-se que as orientações e instrumentos de políticas públicas se alterem à medida que as capacidades tecnológicas acumuladas pelas empresas são modificadas. Ressalta-se a premência de políticas públicas voltadas à inovação, especialmente em produto, na indústria, visto a importância que o setor apresenta para a região e o potencial que pode gerar para esta.

No que tange às contribuições para ações empresariais, os resultados desta pesquisa demonstram que as capacidades tecnológicas não surgem e se desenvolvem em um vácuo, elas necessitam de esforços deliberados e intencionais em aprendizagem. Nesse sentido, sugere-se maior sensibilização das empresas para o desenvolvimento de esforços voltados a diferentes mecanismos de aprendizagem. Sugere-se, inclusive, parceria com universidades, já que praticamente não foram evidenciados mecanismos de aprendizagem em parceria com esse ator. 
Sugere-se, para estudos futuros, a inserção de outras variáveis ( estratégias corporativas, políticas industriais) que corroborem a compreensão das trajetórias de acumulação de capacidades tecnológicas e estudos de caráter quantitativo que apoiem a validação da métrica apresentada no estudo.

\section{REFERÊNCIAS}

Ariffin, N. (2010). Internationalisation of technological innovative capabilities: Levels, types and speed (learning rates) in the electronics industry in Malaysia. International Journal of Technological Learning, Innovation and Development, 3(4), 347-391.

Arrow, K. J. (1962). The economic implications of learning by doing. Review of Economic Studies, 29, 155-173.

Bell, M., \& Figueiredo, P. N. (2012). Building Innovative Capabilities in Latecomer Emerging Market Firms: Some Key Issues. In E. Amann, \& J. Cantwell (Eds.), Innovative Firms in Emerging Market Countries. Oxford: Oxford University Press.

Bell, M., \& Pavitt, K. (1993). Technological accumulation and industrial growth: contrast between developed and developing countries. Industrial and Corporate Change, 2(2), 157 210.

Bell, M., \& Pavitt, K. (1995). The development of technological capabilities. In I. UI Haque, M. Bell, C. Dahlman, S. Lall, \& K. Pavitt, Trade, technology and international competitiveness. Washington: The World Bank.

Dantas, E., \& Bell, M. (2011). The Co-Evolution of Firm-Centered Knowledge networks and Capabilities in Late Industrializing Countries: The Case of Petrobras in the Offshore Oil Innovation System in Brazil. World Development, 39(9), 1570-1591.

Dosi, G., Grazzi, M., \& Mathew, N. (2017). The cost-quantity relations and the diverse patterns of "learning by doing": Evidence from India. Research Policy, 46(10), 1873-1886.

Dougherty, D. (2002). Building Grounded Theory: Some Principles and Practices. In J. A. C. Baum (Ed.), Companion Organization. Oxford, United Kingdom: Oxford Blackwell.

Figueiredo, P., \& Cohen, M. (2019). Explaining early entry into path-creation technological catch-up in the forestry and pulp industry: Evidence from Brazil. Research Policy, 48, 1694-1713.

Figueiredo, P., \& Piana, J. (2018). Innovative capability building and learning linkages in knowledge-intensive service SMEs in Brazil's mining industry. Resources Policy, 58, 21-33. 
Figueiredo, P., \& Piana, J. (2016). When "one thing (almost) leads to another": A micro-level exploration of learning linkages in Brazil's mining industry. Resources Policy, 49, 405-414.

Figueiredo, P. (2001). Technological learning and competitive performance. Cheltenham, K.: Edward Elgar Publishing.

Hansen, U. E., \& Lema, R. (2019). The co-evolution of learning mechanisms and technological capabilities: Lessons from energy technologies in emerging economies. Technological Forecasting and Social Change, 140, 241-257.

Hansen, U. E., \& Ockwell, D. (2014). Learning and technological capability building in emerging economies: The case of the biomass power equipment industry in Malaysia. Technovation, 34(10), 617-630.

Instituto Paranaense de Assistência Técnica e Extensão Rural. (2010). A atividade leiteira na agricultura familiar do sudoeste do Paraná resultados econômicos, período de 2003 a 2006. In Instituto Paranaense de Assistência Técnica e Extensão Rural, Estratégias Metodológicas da Extensão Rural no Paraná. Curitiba: Instituto Emater. Recuperado de http://odiliosepulcri.com.br/pdf/A_atividade_leiteira_na_agricultura_familiar_no_Sudoeste_do_Parana_Resultados_economicos_2003_a_2.pdf

Katz, J., \& Pietrobelli, C. (2018). Natural resource based growth, global value chains and domestic capabilities in the mining industry. Resources Policy, 58, 11-20.

Lacasa, I. D., Jindra, B., \& Radosevic, S. (2018). Technological upgrading and innovation in emerging economies. Int. J. of Technological Learning, Innovation and Development, $10(3-4)$.

Lall, S. (1992). Technological Capabilities and Industrialisation. World Development, 20(2).

Lee, K., \& Lim, C. (2001). Technological regimes, catching-up and leapfrogging: findings from the Korean industries. Research Policy, 30(3), 459-483.

Lee, K., \& Malerba, F. (2017). Catch-up cycles and changes in industrial leadership: Windows of opportunity and responses of firms and countries in the evolution of sectoral systems. Research Policy, 46(2), 338-351.

Lee, H., \& Miozzo, M. (2019). Which types of knowledge-intensive business services firms collaborate with universities for innovation? Research Policy, 48(7), 1633-1646.

Malerba, F. (1992). Learning by firms and incremental technical change. The Economic Journal, 102(413), 845-859. 
Marin, A., \& Bell, M. (2010). The local/global integration of MNC subsidiaries and their technological behaviour: Argentina in the late 1990s. Research Policy, 39, 919-931.

Miao, Y., Song, J., Lee, K., \& Jin, C. (2018). Technological catch-up by east Asian firms: Trends, issues, and future research agenda. Asia Pacific Journal of Management, 35(3), 639-669.

Miles, M. B., \& Huberman, A. M. (1994). Qualitative data analysis. London: Sage Publication.

Patton, M. Q. (2002). Qualitative evaluation methods. Beverly Hills: Sage.

Radosevic, S., Meissner, D., Lacasa, I. D., \& Günther, J. (2019). Exploring technology upgrading of emerging economies: From 'shifting wealth I' to 'shifting wealth II'? Technological Forecasting and Social Change, 145, 254-257.

Secretaria da Comunicação Social. (2015). Agronegócio no Paraná cresce na contramão da crise econômica nacional. Recuperado de http://www.comunicacao.pr.gov.br/modules/ noticias/article.php?storyid $=84599 \&+1+=$ Agronegocio-no-Parana-cresce-na-contramao-da-crise-economica-nacional

Secretaria de Estado da Agricultura e do Abastecimento-Departamento de Economia Rural. (2016). Análise da Conjuntura Agropecuária. Recuperado de http://www.agricultura. pr.gov.br/arquivos/File/deral/Prognosticos/bovinocultura_leite_14_15.pdf

Shan, J. \& Jolly, D. (2012). Accumulation of technological innovation capability and competitive performance: A quantitative study in Chinese electronic information industry. Int. J. of Innovation and Technology Management, 9(5).

Stubrin, L. (2018). Reprint of: Innovation, learning and competence building in the mining industry. The case of knowledge intensive mining suppliers (KIMS) in Chile. Resources Policy, 58, 62-70.

Sutton, J. (2012). Competing in Capabilities: The Globalization Process. Oxford: Oxford University Press.

Tumelero, C., Sbragia, R., Borini, F. M., \& Franco, E. C. (2018). The role of networks in technological capability: A technology-based companies perspective. Journal of Global Entrepreneurship Research, 8(1).

Urzúa, O. (2013). The emergence and development of knowledge intensive mining service suppliers in the late 20th century (Tese de doutorado). University of Sussex, UK. 
Yin, R. (2009). Case Study Research: Design and Methods. (4th ed.). London: Sage.

Yoruk, E. (2011). The influence of technological capabilities on the knowledge network component of innovation systems: Evidence from advanced materials in Turkey. Int. J. Technological Learning, Innovation and Development, 4(4), 330-362.

\section{Como citar este artigo:}

\section{ABNT}

Piana, Janaina; Carvalheiro, Elizângela Mara. Trajetórias de acumulação de capacidades tecnológicas: o caso da indústria leiteira do Sudoeste do Paraná. RACE, Revista de Administração, Contabilidade e Economia, Joaçaba: Editora Unoesc, v. 18, n. 3, p. 475-502, set./ dez. 2019. Disponível em: http://editora.unoesc.edu.br/index.php/race. Acesso em: dia/mês/ ano.

\section{APA}

Piana, J., \& Carvalheiro, E. M. (2019). Trajetórias de acumulação de capacidades tecnológicas: $O$ caso da indústria leiteira do Sudoeste do Paraná. RACE, Revista de Administração, Contabilidade e Economia, 18(3), 475-502. Recuperado de http://editora.unoesc.edu. br/index.php/race 
